\title{
The Low-pressure Casting Technology of aluminum alloy motor
}

\author{
Guoding Yuan ${ }^{\mathrm{a}}$,Hai Gu${ }^{\mathrm{b}}$,Jianhua Sun ${ }^{\mathrm{c}}$,and Zhufeng $\mathrm{LI}^{\mathrm{d}}$ \\ College of Mechanical and Electrical Engineering , Nantong Polytechnic College, Nantong \\ 226002,PR China \\ aemail:gdingy@163.com:, bemail:guhaint@163.com, ${ }^{\mathrm{a} e m a i l: s j h u a n t @ 163 . c o m, ~}{ }^{\mathrm{d}} \mathrm{email}: 782330954 @ q$ \\ q.com
}

Key words: Aluminum alloy; Motor; Low-pressure casting; Process parameters

Abstract: Through the research on low-pressure casting, combined with structure of aluminum alloy, this paper introduces the typical system design of low pressure casting process, including the designs of feeding system and exhaust system. The control techniques of the process parameters which include filling pressure, filling speed and temperature field are studied in the paper to ensure the stability of the quality of the products.

\section{Introduction}

Low-pressure casting is used to produce aluminum alloy castings and magnesium alloy castings which require high quality. Low-pressure casting is an advanced casting production technology. With the development of machinery industry, low-pressure casting has also obtained the very big development in casting production at home and abroad. The emergence of some new technologies and new processes improve the quality of low-pressure casting products, achieving a high rate of finished products. Low- pressure casting is a casting method between pressure casting and gravity casting, with the advantages of smooth liquid mold filling, compact casting structure, high process yield, and of being easy to realize automation, especially suitable for complex, thin-walled castings. Its application in the modern industry is very extensive [1].

The development trend of low-pressure casting technology has the following several aspects[2]:

1) Improve the control accuracy and stability of gas pressure and flow of liquid metal by adopting new pressure way;

2) Combination of low - pressure casting process and a variety of casting process;

3) Low-pressure casting technology of large casting;

4) Low - pressure casting equipments develop towards full automatic, high precision, and large scale.

Low-pressure casting technology is an advanced method of casting process of multi-use, which produces good-quality casting with broad application scope and constant expansion. Meanwhile, more and more researchers begin to pay attention to research and development of low-pressure casting technology, which makes the application prospect of low-pressure casting technology more wide. This paper describes process design of low-pressure casting and its control technology, combining with the design of a motor.

\section{The structure characteristics and process analysis of motor}

Low-pressure casting is a casting method between the gravity casting (such as sand casting, metal casting) and pressure casting. Low-pressure casting means the liquid alloy fill cavity from 
bottom to up under pressure, then crystallize, solidify, and form under pressure. Because of the relatively low pressure $(22 \sim 70 \mathrm{kPa})$, it's called low-pressure casting.

The casting is carrying parts or load output component which is important to air motor. The motor is the major part of pneumatic diaphragm pump. The material is ZL101A. The diameter is $332 X 206.5 \mathrm{~mm}$. The average wall thickness is more than 4-6mm, and its hot spot is thick. The motor structure belongs to heavy parts with medium thickness. The general pouring weight is more than $16 \mathrm{Kg}$ adding gating system. The internal quality of motor has higher requirements. Casting defects, such as shrinkage, shrinkage cavity, and slag inclusion are not allowed. Low-pressure casting has the advantages of low labor intensity, smooth filling velocity, and high process yield. It has some other advantages including hot spot feeding under pressure, low casting temperature, $15 \%-20 \%$ higher mechanical properties of the same material than the gravity casting, and stable and reliable casting quality. In this paper, as shown in Figure 1, the motor parts is $9 \mathrm{Kg}$ in net weight, $5 \mathrm{~mm}$ in thickness of average wall, $10 \mathrm{~mm}$ in thickness of the side flange wall. The diameter of nut boss hot spot is more than $20 \mathrm{~mm}$. the maximum hot spot circle diameter is $42 \mathrm{~mm}$, and dispersed-installed. Low-pressure casting process is used in casting the motor. The process design focuses on feeding scheme, exhaust method, selection and control of the production process parameters.

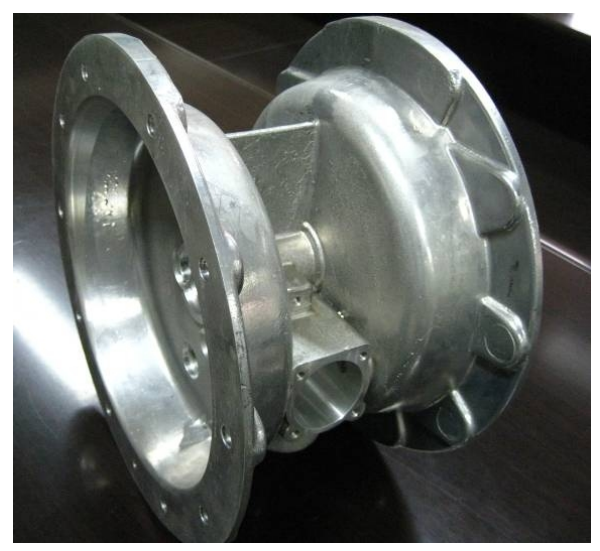

Fig. 1 aluminum alloy motor

\section{System design of low-pressure casting process of the motor}

\section{Feeding characteristic of low-pressure casting process}

The feeding control of Low-pressure casting process is different from that of the gravity casting. For gravity casting, molten metal feeding means liquid aluminum in the riser is guarantee static pressure, and moves from top to bottom, from high temperature region to the low temperature area by gravity. For Low- pressure casting, molten metal filling is the pure bottom pouring type. When outside pressure is put, the feeding is from bottom to up, from high temperature region to the low temperature zone. Without outside pressure, the feeding acts the same way as gravity casting. In the gating process, the upside-down temperature gradient distribution and poor heat dissipation condition of lower die make the top riser design in low-pressure casting $20 \%$ over the gravity casting parts, and even more. Key feeding area of casting, the areas with strongest feeding capacity in the process system shall be arranged in the lower die [3]. 


\section{Design of low-pressure casting gating system}

When Low-pressure casting is adopted, molten metal fills from bottom to top, and the mold filling process is smooth with small turbulence and less oxidation. Exhaust direction of noninvolved gas cavity is in accord with the filling direction of molten metal and the cavity is in good exhaust condition. The gating system has relatively lower requirements for deslagging function, and clean aluminum liquid can even cancel deslagging. The runner design mainly meets the feeding needs, with due consideration to exhaust and filling. As the example listed above, the size structure of the sprue gate and runner are designed according to the requirements for the feeding channel. Casting speed is mainly controlled by filling pressure of pneumatic system and inflow flow, and less influenced by runner structure. But it should be noted that the section size of "actual gate" that runner and casting lap can meet the need of the filling velocity. As the mold temperature is higher in the lower die, the hot spot mainly relies on the efficient runner feeding in the lower die. Short runner brings about a higher rate of process yield. Design of large casting runner, based on full consideration of the feeding requirements, needs attention to the impact of large temperature gradient, bringing with high temperature molten metal, on production efficiency. The thick runner may need longer pressure holding time and solidification time [3].

The Figure 2 above shows the motor structure and hot spot distribution. The distribution of hot spot is divided into three key areas: the lifting screw zone on the side of the casting, the flange zone of flange ring, the thick wall area around the hole, and the nut boss spreading on top surface and the reinforcing ribs surrounding it.

On the basis of the foregoing, it is reasonable to make runner from the hot spot and flange face to the left and the right respectively. The runner starts from the hot spot circle. The cross gate and sprue gate have successively expanded structures.

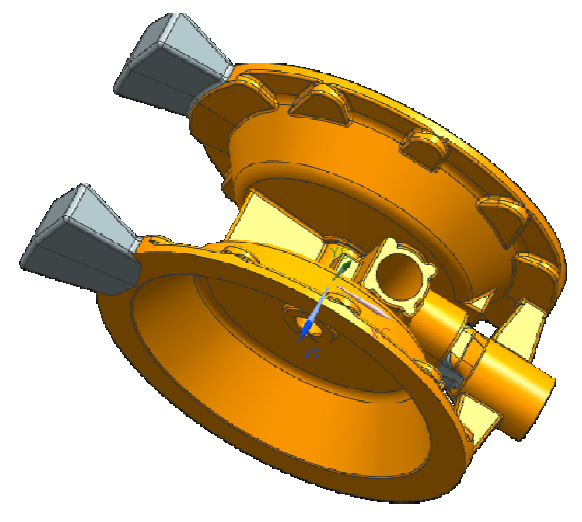

(a) direction 1

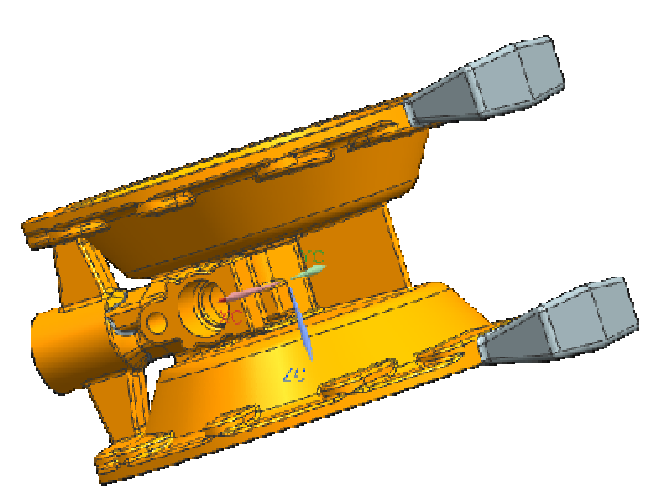

(b)direction 2

Fig.2 Motor gating system

The advantages of this process are as follows: the nut boss scattering on the flange surface is in the end of the flow field of gating system, which is characterized by the shrinkage of the core. Processes as the top riser's feeding and thinned local coating thickness in cavity, coating or copper cooling or other methods can be adopted to control. Reinforcing ribs evenly distributed on the side of casting, which is connected to the annular flange, are shrinking very effectively through the annular flange. In view of the casting shrinkage of the core, as shown in figure 3 , the feeding runner 
in the thick hot spot connected with sprue gate is opened. Four cores fully feed the middle thick part by water cooling. Two runners are set to feed thick nut boss on the annular flange, and reinforcing ribs around fully feed the casting flange.

This feeding system fully and comprehensively covers the casting hot spot, so the defects of shrinkage hole and shrinkage porosity can be avoided effectively.

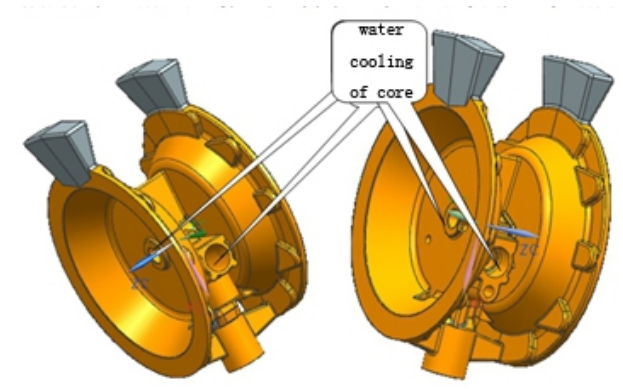

Fig.3 Water cooling passage of core

\section{The design of the exhaust system}

Gas discharge mainly considers two aspects, the gas discharge from cavity and from cavity filling corner.

Cold shut with gas barrier property is very easy to form in the filling blind corner, such as the cavity top and reinforcing ribs. The exhaust design of these places should be attended to while making process design. The main exhaust holes of motor gating system are placed as shown in Figure 4. There is another hole on the side of the mold which can be designed as exhaust channel. The exhaust conditions in these positions must be strengthened in the process. The central hole is designed as movable exhaust duct, so the exhaust can be very smooth. Strengthen the exhaust condition of exhaust plug of upper die, and then ideal results will be gained.

\section{Gating Process Parameters}

The following picture (a typical picture of low-pressure gating process diagram) shows a typical low-pressure casting process control. Of the six stages---lifting, filling, crusting, pressurized solidification, the holding of solidification, and unloading of solidification, the third stage should be fixed according to the needs and usually for thin-wall castings, this stage should be canceled or shortened to the minimum.

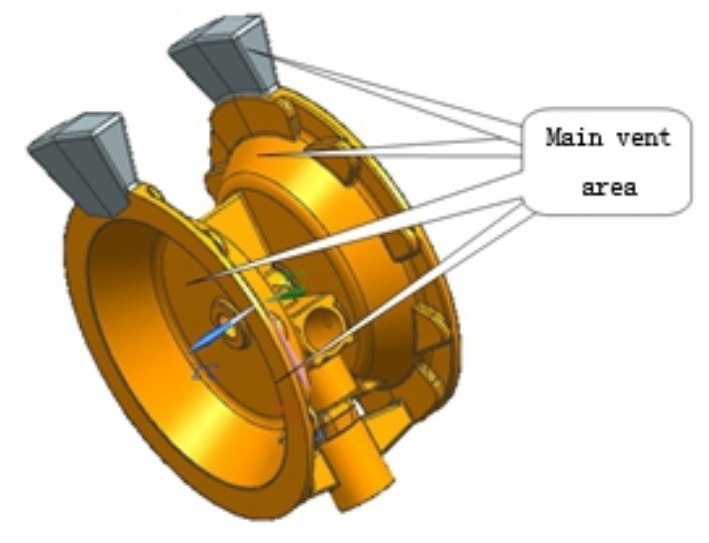

Fig.4 Main vent area of motor gating system

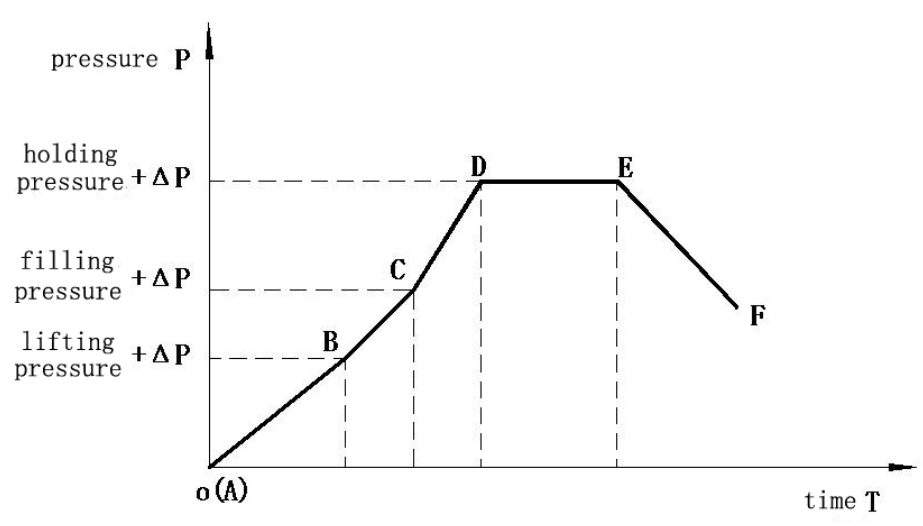

Fig.5 Typical low-pressure gating process graph 1828 
The purpose of lifting pressure is to achieve the uplifting of the liquid metal to the runner gate. With large volume of air, the large slope of A - B section, and the fast speed of lifting, it is effective to improve production efficiency.

Lifting pressure is also called suspended pressure, and the difference between the two pressures is that constant lifting pressure cannot make up for the pressure loss produced by lowering the liquid level in the furnace during the process of production. The liquid level in the furnace in the early stage of mold filling changes dynamically. Suspended pressure $=$ lifting pressure + pressure $\operatorname{loss} \Delta \mathrm{P}$. Therefore, filling pressure parameters of dies can be guaranteed at a certain level stably, while the height of liquid level in the furnace in the early stage of mold filling remains the same.

The purpose of filling pressure is to complete the process of filling metal liquid in the cavity. With a certain ventilation, on the premise of filling, a low pressure can get lower filling speed, can ensure that the cavity gas be discharged fully, improve die gap's ability of sealing liquid metal and undertaking sand cores, and reduce the stomatals of dies and the rejection rate of burnt-on sands.

The main purpose of holding pressure, at present, is to improve the feeding ability of gating system. Generally speaking, the higher the holding pressure is, the better the effect is.

The following are some important processing parameters: lifting pressure is $0.018-0.018 \mathrm{MPa}$; filling pressure is $0.03-0.05 \mathrm{MPa}$; supercharging pressure is $0.05-0.08 \mathrm{MPa}$; and time for filling pressurization is 10 to 20 seconds. Besides, water delivery time is $30-100$ seconds; mold temperature for upper die is $320+40{ }^{\circ} \mathrm{C}$; mold temperature for lower die is $350+50{ }^{\circ} \mathrm{C}$; and temperature for aluminum liquid is $710-720{ }^{\circ} \mathrm{C}$.

\section{Analysis and control of unstable factors of low-pressure casting process}

\section{Unstable factors of low-pressure casting process}

Stability of dies depends on the stability of process parameters. Instable process control is bound to bring casting quality fluctuation. The current low-pressure casting technology has shortages of the following three aspects: temperature control, filling speed and filling pressure.

Temperature control: as a result of the limitation of transferring speed of mold heat, and the periodic changes of heating and cooling conditions, it is difficult to control mould temperature field. As there are great differences between the beginnings and endings of production, the temperature of lower die is relatively lower, and the differences between upper and lower dies are not great. Besides, from running gate to hot spot that needs feeding, the temperature gradient is much smaller than that at the end of the production. The result is the change of feeding conditions, and it's difficult to determine reasonable casting solidification time and filling speed. Crystal structures and mechanical properties of castings in the different periods have great differences $[3,4]$.

Because the heat dissipation area in the lower die is much smaller than that in the upper die. Lower die has more opportunities of heating while upper die can only have dissipation and absorption of heat. Factors like repeatedly washed holding furnace, high temperature furnace, high temperature of liquid aluminum, together with direct contact with high temperature of liquid 
aluminum during the period of pressure solidification, can make the mold temperature gradually close to the temperature of the liquid aluminum. With the increase of working time, the temperature gradient between upper and lower dies becomes bigger and bigger.

The filling speed: Each time a die is casted, furnace cavity volume increases by $\Delta \mathrm{V}$. From "PVT = constant" we know, when the pouring temperature is $\mathrm{T}$ and pressure $\mathrm{P}$ is the fixed parameters, with the increase of the volume $\mathrm{V}$, air inflow is bound to increase. ${ }^{[4]} \mathrm{With}$ constant inlet velocity, inlet time is sure to increase. With the increase of the inlet time, the filling speed will reduce, or the actual state of filling will be delayed. As the actual casting curve of B---C section of the slope is reduced, point $\mathrm{C}$, the filling ending time is delayed step by step, as is shown in Figure 5 . If crust solidified control signal, there will be a pause in the process of liquid metal filling, and the quality of the products will be affected seriously[4].

Filling pressure: Each time a die is casted, furnace drops by $\Delta \mathrm{h}$, and the filling pressure reduces by $\Delta \mathrm{P}$. During the whole work process, parameters of dies' filling pressure are in a dynamic drop.

Temperature control, selection and control of filling speed and filling pressure of low-pressure casting

Temperature control: A stable control of temperature field is one of the primary conditions for quality stability of dies. The selection of equipments, designs and parameters must be controlled. The stability of the temperature, guaranteed by the balance between heat absorption and dissipation, is the primary condition of other parameters. Above all, when designing, appropriate equipments should be chosen based on characteristics of products' structure. Dies with thin walls, big cross sections, and no core cavities has less feeding demands. If a higher filling speed is expected, equipments with low pressure, large flow and large diameter lift pipes can be chosen. Equipments with thick walls, small cross sections, and core cavities has a greater demand, large flow with "high pressure", large diameter lifting pipes and multipoint gating systems can be chosen. Secondly, on the basis of process conditions, a single point of filling should be avoided so as not to cause concentrated feeding and flowing, which will lead to overheating of running area. Next, a suitable mold temperature should be chosen, and the time of coagulation, cooling and mould heating time should be under accurate control to ensure the control of production process is stable and continuous, and the key controlling point on temperature changes is in a reasonable level. As is mentioned in this article, for example, if a temperature setting of the motor's lift tube exit is $400+$ $50{ }^{\circ} \mathrm{C}$, then the control points of lower die is $350+50{ }^{\circ} \mathrm{C}$. When selecting technological parameters of aluminum liquid, faster filling speed, shorter holding time of solidification, and higher pressure of solidification is needed to meet the needs of the filling and feeding[5].

Filling speed: According to the state of equipments, castings, and mold production, the inlet flow can be increased appropriately or the inlet pressure can be controlled. By "PVT = constant", it can be concluded that the speed adjustment can be expressed as: $\operatorname{tn} / \mathrm{tn}+1=\mathrm{Pn} * \mathrm{Vn} /(\mathrm{Pn}=1+\Delta \mathrm{P})(\mathrm{Vn}+1+\Delta \mathrm{V})$. Generally, the filling speed of dies with thin walls, big cross sections and no core cavity is higher than those with thick walls, small cross sections and core cavities. The ideal filling speed depends on the needs of the speed of liquid rising level $\mathrm{V}$, the rising 
speed of metal mold practices recommended, is $10 \mathrm{~mm}$ to $40 \mathrm{~mm} / \mathrm{s}$. The irregular change of casting section $\mathrm{S}$, and the dynamic change of mold temperature field bring the irregular demand of filling speed $\mathrm{Q}(\mathrm{Q}=\mathrm{V} * \mathrm{~S})$, which can be meted by strengthening operation and data processing capacity of the low-pressure equipment unit [6] .

With stable temperature field and proper filling speed, parameters of pressure can help determine a reasonable growth model. By setting the chamber diameter and the weight of a die, using PLC programmable controller, and by making a fixed $\Delta \mathrm{P}$ of pressure parameters according to the working period, the stability of the pressure parameters can be guaranteed.

\section{Conclusion}

Only with profound understanding of method of low-pressure casting technology, comprehensive, reasonable and correct control of various process parameters can we guarantee the stability of the production process and the quality of products. In low-pressure casting, accurate control of technology, temperature, speed, and pressure parameters is necessary to achieve the stable and reliable quality assurance.

\section{Acknowledgments}

The authors are grateful for the Project (CP12014002) supported by the Nantong Science and Technology Commission of China.

\section{References}

[1] X.Z.Xie.Low Pressure Die Casting Mold Design and Process Verification for Engine Aluminum Alloy Cylinder Head.Jiangsu University Master's Degree Thesis.2009,pp231-233.

[2] G.F.Mi, C.Y.Li and K.F.Wang.Numerical Simulation and Application of Low Pressure Die-casting Aluminum Alloy Wheel. Hot Working Technology 2013,Vol.42,No.7,pp60-62.

[3]Lu Gong-hui.Control technology on low pressure casting of aluminum alloy flywheel housing[A].Foundry Institution of Chinese Mechanical Engineering Society.The 5th International Non-ferrous \& Special Conference Proceedings(China)[C].Foundry Institution of Chinese Mechanical Engineering Society:,2007:4.,pp110-113

[4] X.L.Chen.Defect Prediction and Mould Optimization of Aluminum Alloy Wheel Hub in Low Pressure Casting Process. Foundry Technolgy. Vol.35 No.4 Apr. 2014,pp819-821.

[5] L.L.Zhang. Pressure Regulating and Controlling in Low Pressure Casting for Aluminum Alloy. Foundry Technolgy. Vol.34 No.08 Aug. 2013,pp1065-1067.

[6] A.E.Miller, D.M.Maijer.Investigation of erosive-corrosive wear in the low pressure die casting of aluminum A356.Material Science and Engineering,2006,435-436,pp100-111. 